\title{
Article
}

Arq Neuropsiquiatr 2011;69(4):602-606

\section{Cerebellar atrophy is frequently associated with non-paraneoplastic sensory neuronopathy}

\author{
Alfredo Damasceno, Marcondes C. França Jr., \\ Fernando Cendes, Anamarli Nucci
}

\begin{abstract}
Sensory neuronopathies (SN) are peripheral nervous system disorders associated with degeneration of dorsal root ganglion neurons. Despite the evidence of a defective proprioceptive sensory input in $\mathrm{SN}$, the prominent gait and truncal ataxia raises the question of a concomitant involvement of the cerebellum. Objective: To evaluate cerebellar atrophy in SN. Method: We analyzed MRI-based volumetry of anterior lobe (paleocerebellum) and total cerebellum in patients with non-paraneoplastic chronic SN and compared to age- and gender-matched controls. Results: Cerebellum and anterior lobe MRI volumetry were performed in 20 patients and nine controls. Mean anterior lobe and cerebellar volume were not statistically different. Three patients (15\%), however, had an abnormal anterior lobe and cerebellar volume index (values outside 2.5 standard deviations). One of them also had a specific atrophy of the anterior lobe. All these patients had infectious or dysimmune associated SN. Conclusion: Cerebellar atrophy is infrequently associated with $\mathrm{SN}$, but can be found in some patients with $\mathrm{SN}$ related to infectious or immune mediated conditions. It can be more prominent in the anterior lobe and may contribute to the ataxia seen in these patients.
\end{abstract}

Key words: cerebellar atrophy, cerebellar volume reduction, magnetic resonance imaging, sensory neuron disease, sensory neuronopathy

Atrofia cerebelar não é um achado frequente em pacientes com neuronopatia sensitiva não paraneoplasica

\section{RESUMO}

Neuronopatias sensitivas (NS) são distúrbios do sistema nervoso periférico associados com a degeneração dos neurônios do gânglio da raiz dorsal. Apesar da evidência de um defeito das aferências proprioceptivas, a ataxia proeminente da marcha e do tronco levanta a questão de uma participação concomitante do cerebelo. Objetivo: Avaliar a atrofia cerebelar nas NS. Método: Foi analisada volumetria pela ressonância magnética do cerebelo total e do lobo anterior (paleocerebelo) em pacientes com NS crônica não-paraneoplásica e comparada a controles com idades e sexos correspondentes. Resultados: A volumetria do cerebelo e lobo anterior foi realizada em 20 pacientes e nove controles. As médias do volume cerebelar e do lobo anterior não foram estatisticamente diferentes. Três pacientes, entretanto, tiveram um valor anormal do índice de volume

\section{Correspondence}

Alfredo Damasceno Departamento de Neurologia FCM / UNICAMP

13083-970 Campinas SP - Brasil E-mail: alfredodamasceno@ hotmail.com

Conflicts of interest

The authors report no conflict of interest

Received 6 October 2011

Received in final form 22 March 2011

Accepted 08 April 2011 cerebelar e do lobo anterior (valores fora de 2,5 desvios-padrão). Um deles tinha inclusive uma atrofia específica do lobo anterior. Todos esses pacientes tinham NS associada a doenças infecciosas ou disimunes. Conclusão: Atrofia cerebelar é raramente associada com SN, mas pode ser encontrada em alguns pacientes com NS relacionada com doenças infecciosas ou imunológicas. Esta atrofia pode ser mais proeminente no lobo anterior e pode contribuir para a ataxia observada nestes pacientes.

Palavras-chave: atrofia cerebelar, doença do neurônio sensitivo, neuroimagem, neuronopatia sensitiva, volumetria cerebelar.

Department of Neurology, State University of Campinas (UNICAMP), Campinas SP, Brazil. 
Sensory neuronopathies (SN) are peripheral nervous system disorders associated with degeneration of dorsal root ganglion (DRG) neurons. Impairment of large neurons leads to sensory gait ataxia, proprioceptive sensory loss and widespread areflexia, while degeneration of small and medium size neurons causes sensory symptoms such as burning and allodynia ${ }^{1}$. Despite the evidence of a defective proprioceptive sensory input in $\mathrm{SN}$, the prominent gait and truncal ataxia, remarkable even with opened eyes, raises the question of a concomitant involvement of the cerebellum or more specifically, the paleocerebellum ${ }^{2,3}$. Furthermore, cerebellar peduncles and tracts other than posterior columns were involved in a patient with Sjögren syndrome associated $\mathrm{SN}^{4}$.

To evaluate this question we analyzed MRI-based volumetry of anterior lobe (paleocerebellum) and total cerebellum in patients with non-paraneoplastic chronic acquired SN and compared it to age- and gender-matched healthy individuals.

\section{METHOD}

\section{Study design}

We retrospectively reviewed clinical, electrophysiological and cervical spine MRI data of patients referred to our neuromuscular disease outpatient clinic in the last eight years for predominantly sensory disturbances, looking for patients with SN.

Twenty patients were enrolled fulfilling SN criteria which comprised: clinical - sensory ataxia, focal sensory signs, and normal muscle strength; and electrophysiological features - widespread decrease, involving both upper and lower limb nerves, in sensory nerve action potential (SNAP) amplitudes, normal sensory and motor conduction velocities $(\mathrm{CV})$ and normal needle electromyography (EMG). All patients underwent an additional complete neurological evaluation, after giving informed consent. Sensory ataxia was scored according to the functional staging of Friedreich's Ataxia Rating Scale $(\text { FARS })^{5,6}$. Neither patients with molecular genetic confirmation of Friedreich ataxia nor individuals with familial history of neurological disease were included in the study. We performed radiological, hematological, biochemical, and serological screening to investigate malignancies, dysimmune, infectious, metabolic and vitamin disorders. None of our patients had a past history of chronic alcohol intake or phenytoin administration. More detailed methodological aspects are described elsewhere ${ }^{7}$. This study was approved by the ethics committee of the faculty of medical sciences of the University of Campinas (Campinas, Brazil). All subjects that participated in the present study provided signed informed consent.

MRI was performed on a $2.0 \mathrm{~T}$ scanner (Elscint Prestige, Haifa, Israel). Our protocol consisted of cra- nial sagittal T1 spin-echo (3mm thick; 0\% gap; flip angle $=180^{\circ}$; repetition time $=550 \mathrm{~ms}$; echo time $=12 \mathrm{~ms}$; matrix $=270 \times 200$; field of view $=24 \times 24 \mathrm{~cm}$ ), and sagittal T2 ( $3 \mathrm{~mm}$ thick; $0 \%$ gap; flip angle $=110^{\circ}$; repetition time $=4900 \mathrm{~ms}$; echo time $=128 \mathrm{~ms}$; matrix $=320 \times 252$; field of view $=24 \times 24 \mathrm{~cm}$ ). Visual analysis of MRI results was systematically performed by one of us (A.D.), blinded to the clinical data. Volumetric measurements of the cerebellums of all patients were made through a semiautomatic segmentation software (neuroline), previously validated, using sagittal T1 images ${ }^{8}$. The cerebellum was manually outlined on sagittal slices (Fig 1A). The anterior lobe of the cerebellum was outlined in 10 sagittal slices, five to the left of cerebral aqueduct and another five to the right. Its limits were the primary fissure (posterior) and the superior medullary velum (anterior) (Fig 1B).

The cerebellums and anterior lobes of nine healthy volunteers measured with the same criteria were specifically obtained for this study and constituted a control group. Anterior lobe volume (ALV) and cerebellar volume (CEV) were corrected for intracranial volume as follows: Normalized structure volume $=$ (patients' structure volume $\times$ mean cerebral volume of controls)/ patients' cerebral volume. Looking for relative atrophy we also defined the following indexes: RALV and RCEV, calculated as ALV and CEV divided by the total brain volume respectively. A third index created was ALV/ CEV, looking for specific atrophy of anterior lobe. Values smaller than 2.5 SDs (95\% confidence interval) of the control group means were considered abnormal.

\section{Statistical analyses}

Basic demographic, laboratorial, electrophysiological and neuroimaging profile of patients was represented by descriptive statistics. Comparison of means was performed with Mann-Whitney U tests (two independent groups) or Kruskall-Wallis (multigroup comparison). All correlations were made with linear regression (Spearman

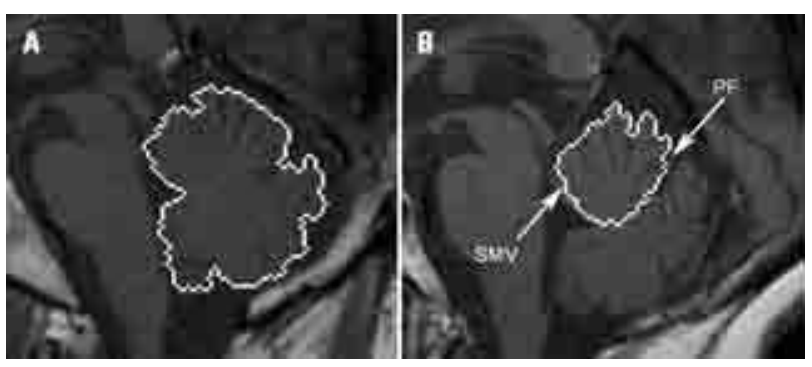

Fig 1. Cerebellum and anterior lobe segmentation. The cerebellum was manually outlined on sagittal slices [A]. The anterior lobe of the cerebellum was also outlined in sagittal slices [B]. Its limits were the primary fissure (PF) posteriorly, and the superior medullary velum (SMV) anteriorly. 
coefficient). Statistical analyses were performed with STATISTICA software (StatSoft, Inc.; Tulsa, OK, USA). The level of significance was established as $\mathrm{p}<0.05$.

\section{RESULTS}

\section{Clinical and laboratorial findings}

Neurological evaluation took place 98 months (range: 30-175) after disease onset. Mean age at evaluation was 50.95 years (range: $20-80$ ). Twelve were female and eight male. Mean age at disease onset was 43 years (range: $17-75), 80 \%$ being between 38 and 55 years. Functional staging for ataxia was 3.45 (range: $2-5$ ) and three patients (15\%) were confined to a wheelchair. SN was associated with dysimmune conditions in six patients: three with Sjögren's syndrome, one with autoimmune active hepatitis, one with monoclonal gammopathy of undetermined significance, and one with unclassified dysimmune syndrome (positive antinuclear antibody (1:320) and elevated sedimentation rate $(45 \mathrm{~mm} / \mathrm{h}$ ) but no other findings). SN was related to active hepatitis $C$ in one patient, who also tested positive for cryoglobulins, to vitamin B12 deficiency in one patient, and to organophosphate intoxication in another. The remaining eleven patients were considered as idiopathic SN (Table). Investigation for malignancies was repeatedly normal. Nine healthy subjects served as a control group. Mean age was 44.77 years (range: $25-$ $59, \mathrm{p}=0.19)$. Two were male and seven female $(\mathrm{p}=0.35)$.

\section{Cerebellum and anterior lobe \\ (Paleocerebellum) MRI findings}

Cerebellum and anterior lobe MRI volumetry were performed in all patients, 97.85 months after disease onset (range 30-175 months). Volumetric measurements (mean CEV, ALV, RALV, RCEV, and ALV/CEV) were not statistically different between patients and controls (Fig 2). Three patients (2, 9 and 10), however, had abnormal RALV and RCEV. One of them (10) also had an abnormal ALV/CEV (Fig 3) and ALV.
There was no significant correlation between volumetric measures and clinical parameters (age at disease onset, disease duration and functional staging of FARS). Groups of SN associated disorders (i.e. dysimmune and idiopathic) showed no difference regarding those volumetric measures. Nonetheless, all patients with abnormal RALV and RCEV had infectious or dysimmune

Table. Clinical data.

\begin{tabular}{|c|c|c|c|c|c|}
\hline Case & $\begin{array}{l}\text { Age/ } \\
\text { Sex }\end{array}$ & $\begin{array}{c}\text { Age at } \\
\text { onset (yr) }\end{array}$ & $\begin{array}{l}\text { Ataxia } \\
\text { score }\end{array}$ & $\begin{array}{l}\text { CS } \\
\text { MRI }\end{array}$ & Etiology \\
\hline 1 & $20 / F$ & 17 & 2 & $\mathrm{NI}$ & Idiopathic \\
\hline 2 & $49 / F$ & 38 & 5 & + & UDS \\
\hline 3 & $47 / M$ & 43 & 5 & + & Idiopathic \\
\hline 4 & $53 / \mathrm{M}$ & 38 & 4 & + & Idiopathic \\
\hline 5 & $46 / F$ & 35 & 4 & + & Sjögren \\
\hline 6 & $65 / F$ & 62 & 4 & $\mathrm{NI}$ & Sjögren \\
\hline 7 & $54 / F$ & 43 & 4 & + & Idiopathic \\
\hline 8 & $53 / \mathrm{M}$ & 39 & 3 & $\mathrm{NI}$ & Idiopathic \\
\hline 9 & $80 / F$ & 75 & 4 & + & Sjögren \\
\hline 10 & $53 / \mathrm{M}$ & 42 & 2 & ND & Hepatitis C \\
\hline 11 & $59 / F$ & 46 & 5 & + & B12 deficiency \\
\hline 12 & $58 / \mathrm{M}$ & 55 & 2 & ND & Idiopathic \\
\hline 13 & $49 / M$ & 42 & 3 & + & OP intoxication \\
\hline 14 & $47 / F$ & 44 & 2 & $\mathrm{NI}$ & Idiopathic \\
\hline 15 & $43 / \mathrm{M}$ & 40 & 3 & + & Idiopathic \\
\hline 16 & 49/M & 41 & 4 & + & Idiopathic \\
\hline 17 & $43 / F$ & 34 & 3 & + & Idiopathic \\
\hline 18 & $51 / F$ & 47 & 2 & + & Idiopathic \\
\hline 19 & $61 / F$ & 52 & 4 & + & MGUS \\
\hline 20 & $39 / F$ & 28 & 4 & + & $\mathrm{AlH}$ \\
\hline
\end{tabular}

+: posterior columns hyperintensisty on cervical spine MRI; AlH: autoimmune hepatitis; ALV/CEV: anterior lobe volume divided by cerebellar volume; CS MRI: cervical spine MRI; MGUS: monoclonal gammopathy of undetermined significance; ND: not done; NI: normal; OP: organophosphate; RALV: relative anterior lobe volume; RCEV: relative cerebellar volume; UDS: unclassified dysimmune syndrome.
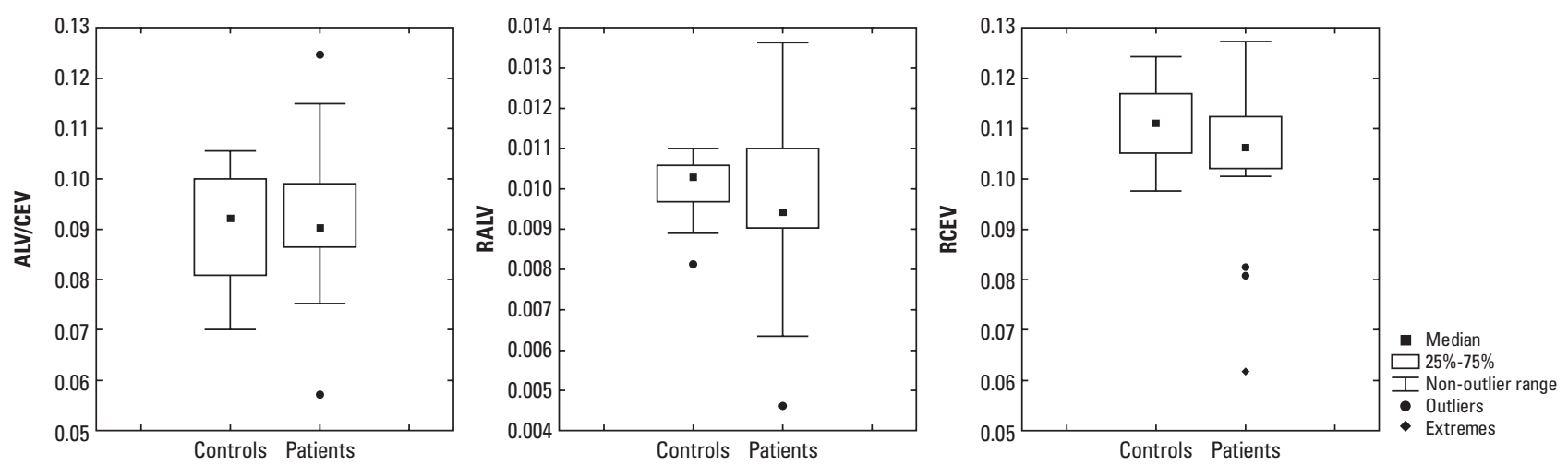

Fig 2. Box-whisker plots of volumetric measures. Mean relative anterior lobe volume (RALV), relative cerebellar volume (RCEV), and ALV/CEV were not statistically different between patients and controls. 

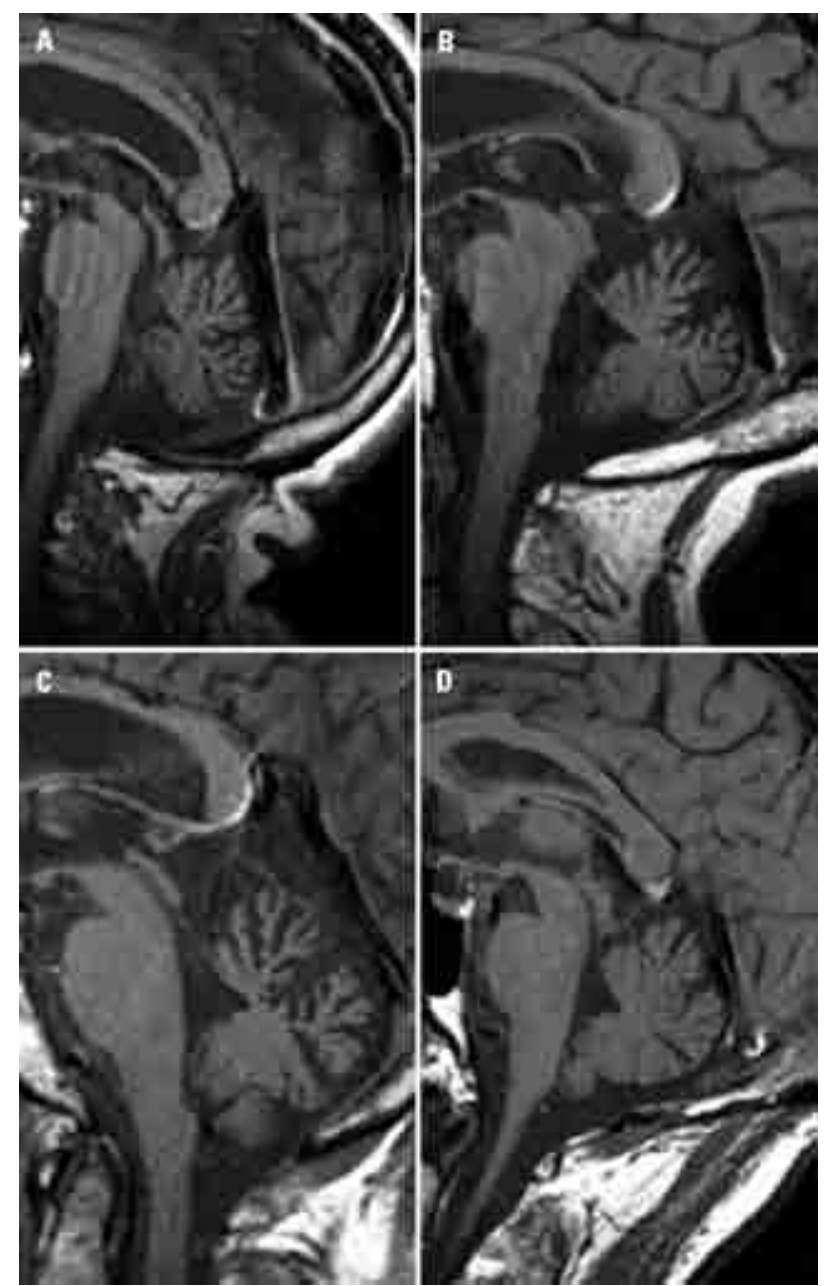

Fig 3. Sagittal cerebellar scans. Cerebellar atrophy is seen in patients $2[A], 9[B]$, and $10[C]$. A preponderant anterior lobe atrophy was found in patient $10[C]$. A normal cerebellum is shown for comparison [D].

associated SN, compared to four of those with normal volumetric parameters $(\mathrm{p}=0.01)$. Patients with abnormal volumetric measures were similar to others regarding clinical parameters and cervical spine MRI ( $p>0.25)$.

\section{DISCUSSION}

Impairment of DRG large neurons causes gait ataxia, proprioceptive sensory loss and widespread muscle stretch areflexia ${ }^{1,9,10}$. In many patients, however, there is a disproportionate gait and truncal ataxia in comparison to limb incoordination, which is also remarkable with preserved visual input, resembling a cerebellar dysfunction. Indeed, involvement of both DRG and cerebellum has been described in paraneoplastic disorders, and, furthermore, serum antibodies directed against a shared epitope in Purkinje cells and DRG neurons have been also reported in patients with SN without malignancies ${ }^{11,12}$. These findings may explain immune mediated concomitant dysfunction of cerebellum and DRG cells in patients with SN. Moreover, recent evidence also showed proximal involvement of the mesencephalon, medial lemniscus and cerebellar peduncles in a patient with Sjögren syndrome associated SN. This finding raised the question of a possible participation of other pathways carrying unconscious proprioceptive information, such as the spinocerebellar tracts, in SN phenotype ${ }^{4}$.

This was a preliminary study that presents some limitations such as a small control group and a simplified acquisition protocol. Despite this, we are able to identify cerebellar atrophy in three patients (15\%) with infectious or dysimmune $\mathrm{SN}$. In one of the patients, the atrophy was even more prominent in the anterior lobe. This lobe, corresponding approximately to the paleocerebellum, receives afferent connections mainly from the anterior spinocerebellar tract through superior cerebellar peduncle, and is involved in locomotion and posture ${ }^{13}$. Damage of such tracts could lead to shrinkage of afferent cerebellar regions. Indeed, degeneration of DRG neurons and spinal cord tracts play a role in the cerebellar and dorsal brainstem atrophy found in Friedreich's ataxia ${ }^{14}$. Alternatively, the associated primary disease may lead directly to both cerebellar and DRG dysfunction. In dysimmune conditions such as Sjögren's syndrome, for example, the immune mediated damage has been implicated as the underlying mechanism for cerebellar ataxia and sensory neuropathies including $\mathrm{SN}^{1,15}$. Although our patient (10) did not have sicca symptoms he did present cryoglobulinemia. Furthermore, none of the patients with idiopathic SN had cerebellar atrophy. Therefore, an immune mediated degeneration of both DRG and cerebellum is a likely explanation, as has been previously described ${ }^{12}$.

We conclude that cerebellar atrophy is infrequently associated with $\mathrm{SN}$, but can be found in rare patients with SN related to infectious or immune mediated conditions. It can be more prominent in the anterior lobe and may contribute to the remarkable gait and truncal ataxia seen in these patients, but further data is needed to better investigate this association. Concomitant cerebellar and DRG dysfunction should prompt dysimmune and hepatitis $C$ investigation.

\section{REFERENCES}

1. Sghirlanzoni A, Pareyson D, Lauria G. Sensory neuron diseases. Lancet Neurol 2005:4:349-361.

2. Lauria G, Pareyson D, Grisoli M, Sghirlanzoni A. Clinical and magnetic resonance imaging findings in chronic sensory ganglionopathies. Ann Neurol 2000;47:104-109.

3. França Jr. MC, D'Abreu A, Zanardi VA, et al. MRI shows dorsal lesions and spinal cord atrophy in chronic sensory neuronopathies. J Neuroimaging 2008;18:168-172.

4. Damasceno A, França Jr MC, Zanardi VA, Nucci A. Brainstem involvement in Sjögren's syndrome-related sensory neuronopathy. J Neuroimaging 2010; 20:397-399.

5. Subramony SH, May W, Lynch D, et al. Cooperative Ataxia Group. Measuring Friedreich ataxia: Interrater reliability of a neurologic rating scale. Neurology 2005;64:1261-1262. 
6. Lynch DR, Farmer JM, Tsou AY, et al. Measuring Friedreich ataxia: complementary features of examination and performance measures. Neurology 2006;66:1711-1716.

7. Damasceno A, França MC Jr, Nucci A. Chronic acquired sensory neuron diseases. Eur J Neurol 2008;15:1400-1405.

8. Carnevalle AD, Rondina JM, Kobayashi E, Cendes F. Validation of a semiautomated system for MRI-based hippocampal volumetry in patients with temporal lobe epilepsy. J Epilepsy Clin Neurophysiol 2003;9:97-104.

9. Denny-Brown D. Primary sensory neuropathy with muscular changes associated with carcinoma. J Neurol Neurosurg Psychiatry 1948;11:73-87.

10. Lauria G, Pareyson D, Sghirlanzoni A. Neurophysiological diagnosis of acquired sensory ganglionopathies. Eur Neurol 2003;50:146-152.

11. Altermatt HJ, Rodriguez M, Scheithauer BW, Lennon VA. Paraneoplastic anti-Purkinje and type I anti-neuronal nuclear autoantibodies bind se- lectively to central, peripheral, and autonomic nervous system cells. Lab Invest 1991:65:412-420.

12. Nemni R, Camerlingo M, Fazio R, et al. Serum antibodies to Purkinje cells and dorsal root ganglia neurons in sensory neuronopathy without malignancy. Ann Neurol 1993;34:848-854.

13. Campbell WW. Coordination and gait. In: Campbell WW (Ed). Dejong's the neurologic examination. Philadelphia: Lippincott Williams \& Wilkins, 2005: 511-534

14. França MC Jr, D’Abreu $A$, Yasuda $C L$, et al. A combined voxel-based morphometry and 1H-MRS study in patients with Friedreich's ataxia. J Neurol 2009;256:1114-1120.

15. Ichikawa H, Ishihara K, Fujimoto R, et al. An autopsied case of Sjogren's syndrome with massive necrotic and demyelinating lesions of the cerebellar white matter. J Neurol Sci 2004;225:143-148. 